\title{
Age and Gender Distribution of Benign Paediatric Odontogenic Tumor: Experience of 30 Cases in Dhaka City
}

\author{
Binay Kumar Das ${ }^{1}$, Mohiuddin Ahmed², Ismat Ara Haider³ ${ }^{3}$ Uday Kumar Goswami ${ }^{4}$, \\ Mohammad Kamorzzaman ${ }^{5}$

\begin{abstract}
${ }^{1}$ Assistant Professor, (Oral and Maxillofacial Surgery), Department of Dentistry, Sheikh Hasina Medical College, Tangail,
Bangladesh; ${ }^{2}$ Professor\& Head, Department of Oral and Maxillofacial Surgery, Sapporo Dental College and Hospital, Dhaka; ${ }^{3}$ Professorand Head, Department of Oral andMaxillofacial Surgery, Dhaka Dental College and Hospital, Dhaka, Bangladesh; ${ }^{4}$ Assistant professor, Oral and Maxillofacial Surgery Dept. Dhaka MedicalCollege, Dhaka, Bangladesh; ${ }^{5}$ Assistant Professor, Department of Dentistry, Sheikh Hasina Medical College,
\end{abstract} \\ Tangail, Bangladesh
}

[Received: 10 April 2019 Accepted: 12 May 2019; Published: 1 July 2019]

\begin{abstract}
Background: Odontogenic tumor can occur among children with the variation of different age and gender. Objective: The purpose of the present study was to see the age and gender distribution of odontogenic benigntumor originated in the oro-facial region among children. Methodology: This cross-sectional study was studied in the department of Oral and Maxillofacial Surgery at Dhaka Dental College and Hospital, Dhaka, Bangladesh from January 2010 to June 2012 for a period of 2 and half year.Children below 18 years of age irrespective of gender, histopathologically diagnosed case of odontogenic tumours were included in this study. Diagnosis of those tumour was done by history, clinical findings and histopathological or cytopathological examination. The clinical, histopathological or FNAC findings were analysed. Result: Among the total benign lesions 30 were odontogenic. In the total odontogenic tumour patients 9 cases were odontogenic keratocyst; 9 cases were ameloblastoma; 5 cases were ameloblastic fibroma; 3 cases were odontogenic myxoma and 4 cases were odontogenic fibroma.Among the patients with odontogenic tumours 15 were less than 10 years old and 15 were 10 to 18 years old. Odontogenic Keratocyst was the most common benign tumour (20.0\%) cases among less than 10 years of age group. In 10 to 18 years of age group the most common reported benign tumour was Ameloblastoma (21.6\%). Male and female ratio was 1.7:1. Among male Ameloblastoma was the most commonly detected benign tumour (17.1\%). Among female childrenodontogenic keratocyst was the most reported tumour (18.8\%). Conclusion: In conclusion the most common odontogenic benign tumour are odontogenic keratocyst and ameloblastoma. [Journal of National Institute of Neurosciences Bangladesh, 2019;5(2): 152-155]
\end{abstract}

Keywords: Age and gender distribution; benign; paediatric odontogenic tumor

Correspondence: Dr. Binay Kumar Das, Assistant Professor, (Oral and Maxillofacial Surgery), Department of Dentistry, Sheikh Hasina Medical College, Tangail, Bangladesh; Email: binay_bd@yahoo.com; Cell no.: 8801711972674

Conflict of interest: There is no conflict of interest relevant to this paper to disclose.

Funding agency: This research project was not funded by any group or any institution.

Contribution to authors: Das BK, Ahmed M, Haider IA contributed from the protocol preparation, data collection up to report writing. Manuscript writing was performed by Das BK; Das BK contributed in statistical model selection and analysis. Goswami UK, Kamorzzaman M have revised the manuscript. Haider IA was involved from the very beginning of this research work up to the revision of the manuscript as a supervisor, guide and director.

How to cite this article: Das BK, Ahmed M, Haider IA, Goswami UK, Kamorzzaman M. Age and Gender Distribution of Benign Paediatric Odontogenic Tumor: Experience of 30 Cases in Dhaka City. J NatlInstNeurosci Bangladesh, 2019;5(2): 152-155

Copyright: (C2019. Das et al. Published by Journal of National Institute of Neurosciences Bangladesh. This article is published under the Creative Commons CC BY-NC License (https://creativecommons.org/licenses/by-nc/4.0/). This license permits use, distribution and reproduction in any medium, provided the original work is properly cited, and is not used for commercial purposes.

\section{Introduction}

Odontogenic tumours are a group of tumours in the orofacial complex arising from tooth forming tissues and is less in the children ${ }^{1}$. Most are slow growing while a few are locally invasive and aggressive causing extensive local destruction. While majority of them are benign, a few are malignant and may metastasize outside the jaws.
The incidence of odontogenic tumours in children is believed to differ according to country ${ }^{2}$. Although there have been some clinic-pathological reports on odontogenic tumours, according to the World Health Organization (WHO), statistical data are available only in certain countries incidence of odontogenic tumour more in males $^{3}$. 
Ameloblastoma is the most common benign tumour $(66.7 \%)$ followed by odontome $(20 \%)$, adenomatoid odontogenic tumour $(10 \%)$ and mandible is the more common site of occurrence for most odontogenic tumours ${ }^{4}$. Gender analysis showed a female predilection for most of the tumours except ameloblastoma 5 . Odontogenic tumours are relatively rare in the child age group; however certain lesions such as adenomatoidodotogenic tumour and ameloblastic fibroma occurs predominantly in children and therefore remain an important diagnostic consideration ${ }^{6}$.

The behavior of lesions depends on whether they are benign or malignant. The classification of oral tumours assists the dentist or oral surgeon in making a decision regarding the nature of the management of tumours since they are generally named after their cells of origin². This present study was undertaken to see the age and gender distribution of odontogenic benigntumor originated in the oro-facial region among children.

\section{Methodology}

This descriptive cross-sectional study was carried out in the department of Oral and Maxillofacial Surgery at Dhaka Dental College and Hospital, Dhaka, Bangladesh. According to inclusion and exclusion criteria patients of age below 18 years were studied from January 2010 to June 2012, who underwent biopsy or fine needle aspiration cytology (FNAC) of tumour for different oro-facial tumours. Study subject were recruited on the basis of inclusion and exclusion criteria and convenient sampling. Children below 18 years of age irrespective of gender, histopathologically diagnosed case of tumours, and Fine needle aspiration cytological diagnosed case of these tumours, parents or legal guardians who gave consent were included in this study. Adult patients above 18 years of age, incomplete clinical data, reports with doubtful and controversial diagnosis, patient with major salivary gland tumours and patient who refused to attained the research were excluded from this study. Diagnosis of those tumour was done by history, clinical findings and histopathological or cytopathological examination. The clinical, histopathological or FNAC findings were analysed. Data were analysed by SPSS, version 12 . Comparison was done by chi-squire test or fisher exact test. Any $\mathrm{p}$ value less than 0.05 was considered statisticallysignificant. Qualitative data were expressed as frequency and percentage. Quantitative data were expressed as mean and standard deviation. Ethical committee of Dhaka Dental College had given the ethical clearance for this study.

\section{Results}

A total number of 30 cases of benign odontogenic tumour cases were recruited for this study. In the total odontogenic tumour patients 9 cases were odontogenic keratocyst; 9 cases were ameloblastoma; 5 cases were ameloblastic fibroma; 3 cases were odontogenic myxoma and 4 cases were odontogenic fibroma (Table $1)$.

Table 1: Type of Odontogenic tumour by origin of dental tissue

\begin{tabular}{lcc}
\hline $\begin{array}{l}\text { Type of benign } \\
\text { Odontogenic tumour }\end{array}$ & Frequency & Percent \\
\hline Odontogenic Keratocyst & 9 & 30.0 \\
Ameloblastoma & 9 & 30.0 \\
Ameloblastic Fibroma & 5 & 16.7 \\
Odontogenic Myxoma & 3 & 10.0 \\
Odontogenic Fibroma & 4 & 13.3 \\
Total & $\mathbf{3 0}$ & $\mathbf{1 0 0 . 0}$ \\
\hline
\end{tabular}

Among the patients with odontogenic tumours 15 were less than 10 years old and 15 were 10 to 18 years old. Odontogenic Keratocyst was the most common benign tumour which was $6(20.0 \%)$ cases among less than 10 years of age group followed by ameloblastic fibroma, odontogenic myxoma and odontogenic fibroma which were $4(13.3 \%)$ cases, $2(6.7 \%)$ cases and $2(6.7 \%)$ cases respectively. In 10 to 18 years of age group the most common reported benign tumour was Ameloblastoma which was $8(21.6 \%)$ cases followed by odontogenic keratocyst and odontogenic fibroma which were $3(8.1 \%)$ cases and $2(5.4 \%)$ cases respectively (Table 2).

Table 2: Individual type of benign Odontogenic tumour by age

\begin{tabular}{lccc}
\hline Type & \multicolumn{2}{c}{ Age Group } & Total \\
\cline { 2 - 3 } & $<\mathbf{1 0}$ years & $\mathbf{1 0}$ to 18 years & \\
\hline Odontogenic Keratocyst & $6(20.0 \%)$ & $3(8.1 \%)$ & $9(30.0 \%)$ \\
Ameloblastoma & $1(3.3 \%)$ & $8(21.6 \%)$ & $9(30.0 \%)$ \\
Ameloblastic Fibroma & $4(13.3 \%)$ & $1(2.7 \%)$ & $5(16.7 \%)$ \\
Odontogenic Myxoma & $2(6.7 \%)$ & $1(2.7 \%)$ & $3(10.0 \%)$ \\
Odontogenic Fibroma & $2(6.7 \%)$ & $2(5.4 \%)$ & $4(13.3 \%)$ \\
Total & $\mathbf{1 5}(\mathbf{1 0 0 . 0 \% )}$ & $\mathbf{1 5 ( 1 0 0 . 0 \% )}$ & $\mathbf{3 0}(\mathbf{1 0 0 . 0 \% )}$
\end{tabular}

*No significant difference was observed (Chi squire test; $p$ value $>0.05$ )

Regarding sex distribution of odontogenic tumours 19 cases were male and 11 cases were female. Male and female ratio was 1.7:1. Among male Ameloblastoma was the most commonly detected benign tumour which was $6(17.1 \%)$ cases followed by ameloblastic fibroma, odontogenic keratocyst, odontogenic myxoma and odontogenic fibroma which were $4(11.4 \%)$ cases and $3(8.6 \%)$ cases each in the rest of the types. Among 
female childrenodontogenic keratocyst was the most reported tumour which was $6(18.8 \%)$ cases followed by ameloblastoma which was $3(9.4 \%$ ) cases (Table 3 ).

Table 3: Individual type of benign tumour by sex

\begin{tabular}{lccc}
\hline Type & \multicolumn{2}{c}{ Gender } & \multirow{2}{*}{ Total } \\
\cline { 2 - 3 } & Male & Female & \\
\hline Odontogenic Keratocyst & $3(8.6 \%)$ & $6(18.8 \%)$ & $9(30.0 \%)$ \\
Ameloblastoma & $6(17.1 \%)$ & $3(9.4 \%)$ & $9(30.0 \%)$ \\
Ameloblastic Fibroma & $4(11.4 \%)$ & $1(3.1 \%)$ & $5(16.7 \%)$ \\
Odontogenic Myxoma & $3(8.6 \%)$ & $0(0.0 \%)$ & $3(10.0 \%)$ \\
Odontogenic Fibroma & $3(8.6 \%)$ & $1(3.1 \%)$ & $4(13.3 \%)$ \\
Total & $\mathbf{1 9 ( 1 0 0 . 0 \% )}$ & $\mathbf{1 1 ( 1 0 0 . 0 \% )}$ & $\mathbf{3 0 ( 1 0 0 . 0 \% )}$ \\
\hline
\end{tabular}

*No significant difference was observed (Chi squire test; $p$ value $>0.05$ )

\section{Discussion}

Tröbs et $\mathrm{al}^{7}$ have demonstrated that the vast majority of oral lesions in infants and children is mesenchymal nature and is benign in character ranging from $84.0 \%$ to $99.0 \%$ of cases. This finding is not agreed with others as Nazimiet $\mathrm{al}^{8}(9.5 \%)$, Arotiba et $\mathrm{al}^{9}(40.2 \%)$ and Varkhede et $\mathrm{al}^{2}(13.3 \%)$. Incidence of malignancy observed range of 1 to $16.0 \%$ reported by other European and North American studies ${ }^{3,7}$ while the exceedingly high rate of $40 \%$ malignant tumours in Nigerian children is attributable to the high prevalence of Burkkit's lymphoma in that population'. In another study ${ }^{10}$ it has been observed a 4 to 5 percent of Ewing's sarcoma; however, in this study found $2.8 \%$ cases of 71 patients. The low percentage of malignant tumours in this study could be due to the following reasons: inclusion of patients aged 18 years and below, inclusion of also tumour-like lesions in this study, and possibly, less sample size. It was found that malignant tumours affects equally in male female (1:1). Elarbi et $\mathrm{al}^{11}$ reported that the male female ratio is 1.6:1. Most of the previous studies have found similar ratio with a high male predominance?

In the total odontogenic tumour patients 9 cases were odontogenic keratocyst; 9 cases were ameloblastoma; 5 cases were ameloblastic fibroma; 3 cases were odontogenic myxoma and 4 cases were odontogenic fibroma. Odontogenic tumours were $44.8 \%$ in this study among the all benign tumours. Keszler et $\mathrm{a}^{12}$ and Maatia ${ }^{13}$ describe that the rate of odontogenic tumours varies between $19 \%$ and $33.7 \%$. Odontogenic tumours are found more often in male patients and ratio was 1.72:1, which is supported by Arotiba et $\mathrm{al}^{9}$ in contrast female predominant is reported by Tröbs et $\mathrm{al}^{7}$. In another study ${ }^{14}$ mostly encountered odontogenic tumour is benign in nature with only $4.5 \%$ being of malignant variety of which ameloblastoma is accounted for $69.2 \%$, fibromyxoma $(12.5 \%)$, adenomatoid odontogenic tumour (4.6\%) and ameloblastic fibroma (3.1\%).

Various reports in the literature of Adebayoet $\mathrm{al}^{14}$ and Nazimi et $\mathrm{al}^{15}$ confirm the rarity of odontogenic tumours in children and adolescents. These authors used various age categories for their subjects and considered odontogenic tumours within the spectrum of orofacial neoplasm's. According to Ulmanskyet $\mathrm{al}^{16}$ between 1.0 and $28.8 \%$ of pediatric oral lesions are odontogenic tumours. In this series of oral tumours in children and adolescent $\leq 18$ years old, $44.8 \%$ are odontogenic tumours. While this result is higher than the worldwide range given by Ulmansky et $\mathrm{al}^{16}$. However in another study ${ }^{4}$ it has been observed that high prevalence of odontogenic tumour in young age while rare in children below 10 years of age. In contrast Arotiba et $\mathrm{al}^{9}$ shows odontogenic tumours the male female ratio in 1.6:1. which is supported by this study.

Ameloblastoma occurred in 9 patients below 18 years old representing $30 \%$ of odontogenic tumours. Study shows that there are more in males $(14.7 \%)$ than females $(6.5 \%)$ and ratio was $5: 2$, while Nazimi et al ${ }^{15}$ and Schafer et $\mathrm{al}^{17}$ demonstrate the ratio 2:1 which is very close to this present study. Study about Ameloblastoma by Schafer et $\mathrm{al}^{17}$ shows that $33.4 \%$ patients are within the age range between 10 to 19 years. In this study among the total patients 1 patient were in the age group below 10 years of age and another 8 patients were in between 10 to 18 years of age.

In this study ameloblastic fibroma represents $16.7 \%$ of total benign odontogenic tumour. All are below 10 year of age with a male female ratio of $4: 1$. Among the tumour 4 in mandible and 1 in other side. In contrast Ulmansky et $\mathrm{al}^{16}$ shows Ameloblastic fibroma is rare accounting for less than $7.0 \%$ of odontogenic tumour, male female ratio was $2: 1$ and occurred in younger age group. Age group of ameloblastic fibroma in this study is 4 in age group below 10 and 1 is the age in between 10 to 18 years of old.

This study has been conducted in a particular tertiary hospital, so the findings cannot reflect the general scenario of the country. The relatively small sample size is another limitation in this study.

\section{Conclusion}

In conclusion, odontogenic benign tumour are found in all ages of children. The most common odontogenic 
benign tumour among paediatric age group are odontogenic keratocyst and ameloblastoma. However, ameloblastoma is the most commonly detected benign tumour among male. Furthermore, odontogenic keratocyst is most frequently found in female.Further large scale study should be carried out.

\section{References}

1. Parkins GE, Armah G, Ampofo P. Tumours and tumour-like lesions of the lower face at Korle Bu Teaching Hospital, Ghana-an eight year study. World journal of surgical oncology. 2007;5(1):48 2. Varkhede A, Tupkari JV, Mandale MS, Sardar M. Odontogenic tumors: a review of 60 cases. J ClinExp Dent. 2010;2(4):e183-6 3. Adebayo ET, Ajike SO, Adekeye EO. Tumours and tumour-like lesions of the oral and perioral structures of Nigerian children. International journal of oral and maxillofacial surgery. 2001;30(3):205-8

4. Dhanuthai K, Banrai M, Limpanaputtajak S. A retrospective study of paediatric oral lesions from Thailand. International journal of paediatric dentistry. 2007;17(4):248-53

5. Al-Khateeb T, Hamasha AA, Almasri NM. Oral and maxillofacial tumours in north Jordanian children and adolescents: a retrospective analysis over 10 years. International journal of oral and maxillofacial surgery. 2003;32(1):78-83

6. Iatrou I, Theologie-Lygidakis N, Tzerbos F, Schoinohoriti OK. Oro-facial tumours and tumour-like lesions in Greek children and adolescents: an 11-year retrospective study. Journal of Cranio-Maxillofacial Surgery. 2013;41(5):437-43

7. Tröbs RB, Mader E, Friedrich T, Bennek J. Oral tumors and tumor-like lesions in infants and children. Pediatric surgery international. 2003 Nov 1;19(9-10):639-45

8. Nazimi AJ, Hani HF, Rifqah N, Razif MM, Putra SP. P86.
Tumours and tumour-like lesions of the oral cavity and related structures presented in UKM Medical Centre: A two-year study. Oral Oncology. 2011(47):S101

9. Arotiba JT, Ajike SO, Akadiri OA, Fasola AO, Akinmoladun VI, Adebayo ET, Okoje VN, Kolude B, Obiechina AE. Odontogenic tumours: analysis of 546 cases from Nigeria. J Oral Maxillofac Surg. 2007;6:44-50

10. Ord RA, BlanchaertJr RH, Nikitakis NG, Sauk JJ. Ameloblastoma in children. Journal of oral and maxillofacial surgery. 2002;60(7):762-70.

11. Elarbi M, El-Gehani R, Subhashraj K, Orafi M. Orofacial tumors in Libyan children and adolescents. A descriptive study of 213 cases. International journal of pediatric otorhinolaryngology. 2009;73(2):237-42

12. Keszler A, Guglielmotti MB, Dominguez FV. Oral pathology in children. Frequency, distribution and clinical significance. ActaOdontologicaLatinoamericana1990;5:39-48

13. Maaita JK. 2000Oral tumours in children: a review. J ClinPediatr Dent 2000;24: 134-137

14. Adebayo ET, Ajike SO, Adekeye EO. A review of 318 odontogenic tumors in Kaduna, Nigeria. Journal of oral and maxillofacial surgery. 2005;63(6):811-9

15. Nazimi AJ, Hani HF, Rifqah N, Razif MM, Putra SP. P86. Tumours and tumour-like lesions of the oral cavity and related structures presented in UKM Medical Centre: A two-year study. Oral Oncology. 2011(47):S101

16. Ulmansky M, Lustmann J, Balkin N. Tumors and tumor-like lesions of the oral cavity and related structures in Israeli children. International journal of oral and maxillofacial surgery. 1999;28(4):291-4

17. Schafer DR, Thompson LD, Smith BC, Wenig BM. Primary ameloblastoma of the sinonasal tract: a clinicopathologic study of 24 cases. Cancer: Interdisciplinary International Journal of the American Cancer Society. 1998;82(4):667-74. 